\title{
HUMAN CAPITAL CHALLENGES IN INDONESIA AND WELCOME ASEAN ECONOMIC COMMUNITY (AEC) in 2015
}

\author{
Muhamad Rizal \\ Business Administration Lecturer \\ Faculty of Social Science and Political Science, Padjadjaran University \\ Email: rizal.unpad@gmail.com
}

\begin{abstract}
Charter and ASEAN blueprint towards the ASEAN Economic Community (AEC) in 2015, has been agreed by the members, characterized by a new round of joint commitment that is legally binding. AEC Blueprint will give direction of ASEAN as a regional production base and single market. The blueprint is supported by the five essential pillars namely: the free flow of goods, services, investment, skilled labor, and freer flow of capital. Efforts to realize the ASEAN as a regional production base and single market is certainly provides a lot of great opportunities and challenges for Indonesia. In this regard, the main sectors which require improvement are professional human capital and competent. Without improvements in this sector, efforts to achieve the Indonesian government for human capital to compete with other countries in Southeast Asia will be difficult. Therefore, in facing such competition, the Indonesian government should prepare a Human Resources (HR) were skilled, intelligent and competitive that Indonesian human resources able to compete.
\end{abstract}

Keywords : AEC, Human Capital, Professional and Competent

\section{HUMAN CAPITAL INDONESIA DAN TANTANGANNYA \\ DALAM MENYONGSONG MASYARAKAT EKONOMI ASEAN (MEA) 2015}

\begin{abstract}
ABSTRAK
Piagam dan cetak biru ASEAN menuju Masyarakat Ekonomi ASEAN (MEA) 2015, telah disepakati para anggotanya, ditandai dengan babak baru komitmen bersama yang mengikat secara hukum. Cetak biru MEA ini akan memberikan arah ASEAN sebagai sebuah kawasan basis produksi dan pasar tunggal. Cetak biru ini ditopang oleh lima pilar penting yaitu: aliran bebas dari barang, jasa, investasi, tenaga kerja terampil, dan aliran modal yang lebih bebas. Upaya mewujudkan ASEAN sebagai kawasan basis produksi dan pasar tunggal ini tentu saja memberikan banyak peluang sekaligus tantangan yang besar bagi Indonesia. Dalam kaitan ini, sektor-sektor utama yang memerlukan pembenahan dalam human capital yang profesional dan kompenten.Tanpa pembenahan di sektor ini, upaya pencapaian target pemerintah agar human capital Indonesia bersaing dengan negara-negara lain di kawasan Asia Tenggara akan terasa sulit. Oleh karenanya dalam mengahadapi persaingan tersebut, pemerintah Indonesia harus mempersiapkan sumber daya manusia (SDM) yang trampil, cerdas dan kompetitif sehingga SDM Indonesia mampu bersaing.
\end{abstract}

Kata kunci : MEA, human capital, profesional dan kompeten 


\section{PENDAHULUAN}

Tahun 2016 ini adalah awal sepuluh negara di wilayah Asia Tenggara yang tergabung dalam ASEAN mengintegrasikan diri dalam suatu kawasan integrasi ekonomi.Tujuan ideal MEA sendiri sebenarnya sudah tercetus sejak tahun 1997 yang tercermin dalam Visi ASEAN 2020 yaitu mewujudkan kawasan yang stabil, makmur dan berdaya saing tinggi dengan pembangunan ekonomi yang merata yang ditandai dengan penurunan tingkat kemiskinan dan perbedaan sosial ekonomi. Selanjutnya dalam KTT ASEAN tahun 2003 di Bali disepakati pilar-pilar untuk menopang tujuan yang terdapat dalam Visi ASEAN 2020 yaitu pilar keamanan; pilar ekonomi; dan pilar sosial budaya. (www.deplu.go.id)

Untuk pilar ekonomi dalam bentuk Masyarakat Ekonomi ASEAN yang bersama kedua pilar lainnya dapat terwujud pada tahun 2020. Dalam mewujudkan Masyarakat Ekonomi ASEAN tahun 2020, disepakati proses liberalisasi di wilayah ASEAN dengan tujuan mencapai integrasi pada tahun 2010 untuk 11 sektor yang diprioritaskan yaitu Agrobased Products; Air Travel; Automotive; eASEAN; Electronics; Fisheries; Healthcare; Rubber-based products; Textiles \& Apparels; Tourism; Wood-based products, dan pada tahun 2005 ditambah dengan Logistic Services.

Oleh karenanya, untuk mencapai tujuan integrasi ekonomi ASEAN 2020 disepakati 12 sektor prioritas yang terdiri dari 7 sektor barang dan 5 sektor jasa. Keinginan bagi tujuan mengintegrasikan perekonomian di kawasan ASEAN tampaknya semakin mantap sehingga pada KTT ASEAN Januari 2007, target tahun 2020 dipercepat menjadi tahun 2015. Salah satu tujuannya adalah membuat ASEAN sebagai satu wilayah dimana barang, jasa, investasi, tenaga kerja yang punya keahlian dapat lalu lalang secara bebas, dan adanya aliran permodalan yang lebih bebas.

Selanjutnya para kepala negara anggota ASEAN mengeluarkan suatu Deklarasi yang mengesahkan suatu cetak biru untuk mewujudkan komunitas ekonomi ASEAN (Declaration on the ASEAN Economic Community Blueprint) pada bulan Nopember 2007. ASEAN Economic Community Blueprint (AEC Blueprint) dirancang untuk transformasi ASEAN kepada "a single market and production base, a highly competitive economic region, a region of equitable economic development, and a region fully integrated into global economy". Artinya tekad, semangat, landasan dan tujuan untuk mencapai tujuan ideal tersebut sudah tersedia. Sisanya tinggal tergantung kita semua baik pemerintah maupun rakyatnya untuk melaksanakan dan mewujudkan cita-cita itu.

Masyarakat Ekonomi ASEAN, adalah komunitas regional Asia Tenggara yang memiliki visi bersama untuk kemajuan bersama. Oleh karenanya, pemerintah Indonesia dituntut untuk meningkatkan sumberdaya insani bangsa Indonesia. Pemerintah Indonesia harus mampu mempersiapkan human capitalnya untuk bersaing dengan negara-negara ASEAN lainnya. Hal ini menjadi penting karena Indonesia adalah negara terbesar di kawasan ini yang memiliki sumberdaya manusia maupun sumberdaya alam.

Salah satu rencana ASEAN sendiri dalam hal pilar ekonomi, ada perkembangan yang sangat mendasar pada ASEAN sebagai organisasi yaitu disepakatinya "ASEAN Charter" dalam rangka peringatan 40 tahun berdirinya ASEAN bulan Nopember 2007 di Singapura. Diputuskan oleh para kepala negara ASEAN melalui "ASEAN Charter" ini adanya "legal and institutional framework for ASEAN". Keputusan untuk menyepakati ASEAN Charter ini sangat strategis bagi ASEAN sebagai organisasi kawasan karena dalam Charter ini mengatur tentang Tujuan dan Prinsip, kedudukan hukum organisasi ASEAN, Keanggotaan, Kelembagaan Organisasi, Entitas yang terkait dengan ASEAN, Imunitas dan Hak-hak Istimewa, Proses Pembuatan 
keputusan, Penyelesaian sengketa, Anggaran dan pembiayaan, Administrasi dan Prosedur, Hubungan Eksternal, dan Ketentuan Akhir dan Umum. (ASEAN 2025 : Forging ahead Together,59)

Dokumen ini sangat penting bagi ASEAN sebagai suatu organisasi kawasan termasuk juga dalam hal pelaksanaan programprogramnya saat ini dan kedepan. Kepentingan ASEAN termasuk dalam mewujudkan cita-cita pilar ekonomi yaitu terbentuknya AEC 2015. Dari segi teknis operasional, pelaksanaan AEC Blueprint adalah kerja besar bagi ASEAN termasuk Indonesia tentunya. Tugas berat bagi kementerian di Indonesia yang harus menangani dan mengkoordinasikan pelaksanaan AEC Blueprint. Pekerjaan yang harus dilakukan kementerian ini harus mengkoordinasikan sedemikian banyak kepentingan sektor yang dicakup dalam AEC Blueprint misalnya sektor perdagangan (barang dan jasa), investasi, tenaga kerja dan sebagainya. Belum lagi elemen-elemen yang dicakup seperti Kebijakan persaingan, hak kekayaan intelektual, perpajakan, usaha kecil menengah, pembangunan infrastruktur, permodalan, e-commerce dan lain-lain. Beban lainnya adalah jangka waktu pelaksanaan yang ditetapkan dalam AEC Blueprint yaitu 20082009, 2010-2011, 2012-2013, dan 2014-2015.

Semuanya itu hanya bisa terlaksana baik bilamana ada koordinasi yang baik dan semua elemen masyarakat bisa dilibatkan. Dengan adanya "ASEAN Charter" maka perlu adanya kepastian bahwa Charter ini dapat diselesaikan proses Ratifikasinya. Ratifikasi Charter ini sangat penting bagi landasan kerja untuk ketiga pilar yaitu keamanan, ekonomi, dan sosial budaya. Ibarat membangun gedung bertingkat, bagaimana mungkin dapat menyelesaikan pembangunan gedung itu sementara fondasinya belum disetujui buat dipakai. Apalagi kalau fondasi yang sudah disepakati bersama itu nggak boleh dipasang atau terlambat dipasang. Pembangunan gedung itu dipastikan bakal terlambat. Kalaupun pilar ekonominya dibangun terus tanpa memperhatikan fondasi yang dipakai, bisa dipastikan pilar tersebut juga "goyang". Itupun masih lumayan sepanjang nggak malah "ambruk". Jadi selain masalah fondasi yaitu yang menyangkut perlunya diratifikasinya "ASEAN Charter", juga perlu kesiapan semua sektor perekonomian terkait kalau kita ingin mengambil manfaat dari keberadaan AEC 2015.

Efek globalisasi dan kesuksesan integrasi ekonomi Eropa dalam bentuk pasar tunggal yang digodok sejak 1950-an sedikit banyak menginspirasi wilayah lain. Asia Tenggara menjadi wilayah yang kemudian mengikuti langkah ini. Isu integrasi ekonomi ASEAN mulai dipelajari tahun 1997 ketika badai krisis ekonomi global menerpa. Negara-negara anggota ASEAN berharap Masyarakat Ekonomi ASEAN (MEA) bisa menjadi fondasi kokoh ketika diwujudkan tiga tahun mendatang.

ASEAN sangat berkepentingan membentuk pakta ekonomi yang kokoh, saling melindung dan bersifat timbal balik karena kawasan ini adalah pasar dan wilayah investasi terbesar dari negara-negara industri. Tentu saja di luar kepentingan ekonomi, geopolitik ASEAN kini semakin penting karena menjadi kawasan perimbangan kekuatan Amerika Serikat, Eropa, Jepang, Rusia dan China. Satu negara yang bergantung namun terkesan gengsi melakukan pendekatan dalam taraf setara adalah Australia yang berada di utara. Tanpa ASEAN, Australia akan menjadi benua mini yang terasing.Tahun 2007, di usia ke-40, 10 negara-negara Asia Tenggara menyepakati Piagam ASEAN dan Cetak biru ASEAN menuju Masyarakat Ekonomi ASEAN (MEA) 2015, pada Konferensi Tingkat Tinggi ASEAN ke-13 di Singapura.

Penandatangan Piagam ASEAN ini akan menandai babak baru ASEAN menuju sebuah organisasi dengan komitmen bersama yang mengikat secara hukum. Sedangkan cetak biru MEA akan memberikan arah bagi perwujudan 
ASEAN sebagai sebuah kawasan basis produksi dan pasar tunggal. Pencapaian MEA ini dilakukan melalui lima pilar, yaitu: aliran bebas dari barang, jasa, investasi, tenaga kerja terampil, dan aliran modal yang lebih bebas. Upaya mewujudkan ASEAN sebagai kawasan basis produksi dan pasar tunggal ini tentu saja memberikan banyak peluang sekaligus tantangan yang besar bagi Indonesia. (ASEAN 2025: Forging ahead together 60)

Semua pihak tahu betul pesoalan mewujudkan MEA justru terletak pada institusi ASEAN yang ada tidak cukup memiliki kewenangan atau otoritas dalam menentukan berbagai kebijakan ekonomi. Lewat studi kasus Uni Eropa, paper ini berusaha menyampaikan bahwa titik lemah MEA ada pada lemahnya koordinasi lintas sektoral terutama mekanisme fasilitasi perdagangan untuk memperlacar arus barang, mengurangi biaya tinggi serta meningkatkan efisiensi.

Dalam kaitan ini, sektor-sektor utama yang memerlukan pembenahan adalah transportasi dan komunikasi serta bea-cukai. Tanpa pembenahan ketiga sektor ini, perberlakuan MEA pada awal tahun 2016 akan terasa amat sulit.Satu contoh jelas adalah hambatan di sektor jasa yang gagal dipecahkan ASEAN Secretariat yang memang kurang diberi kewenangan dalam pengambilan keputusan untuk mendorong laju integrasi ekonomi. Namun di tengah rencana besar ini, MEA juga menyimpan kegundahan bagi Indonesia untuk mampu bersaing sederajad dengan anggota ASEAN lain terutama kemampuan SDM Indonesia.

Sebagai contoh, sudah siapkah para petani Indonesia untuk bersaing dengan para petani dari Thailand dan Vietnam yang sukses membanjiri pasar domestik dengan produk mereka yang murah dan lebih berkualitas? Begitu juga industri tekstil Indonesia yang masih megap-megap digempur produk China. Sejauh ini industri tekstil Vietnam, Kamboja, dan Malaysia masih di atas angin. SDM
Indonesia secara umum diakui atau tidak masih tertinggal. Bahkan untuk sumber daya pembantu rumah tangga pun, Indonesia kalah dengan Filipina yang lebih profesional.tulisan ini berusaha menganalisis dan menjelaskan apakah Indonesia akan menjadi sekadar penonton atau menjadi pemain yang diperhitungkan negara-negara lain ASEAN.

1. Apa yang menjadi kendala dan tantangan Human Capital Indonesia menyongsong MEA 2015?

2. Upaya-upaya apa saja yang telah dilakukan dalam meningkatkan Human Capital Indonesia Indonesia menyongsong MEA 2015?

\section{METODE PENELITIAN}

Obyek yang diteliti adalah tentang Kesiapan Human Capital Indonesia Dalam Menyongsong Masyarakat Ekonomi ASEAN. Aspek bahasannya meliputi sudut pandang hukum, ekonomi dan politik.

Penelitian ini dilakukan dengan menggunakan studi literatur, Khususnya yang berkaitan dengan Human Capital dan Masyarakat Ekonomi ASEAN.

Penelitian ini akan menggunakan desain penelitian kualitatif dengan metoda deskriptif untuk menjelaskan situasi, kondisi dan segala permasalahan yang dihadapi obyek penelitian senyatanya agar diperoleh pemahaman makna secara mendalam.

\section{HASIL PENELITIAN DAN PEMBAHASAN}

Ada delapan profesi yang akan terkena dampak kebijakan pasar bebas yang tertuang dalam ASEAN Mutual Recognition Arrangement (MRA). MRA masing-masing profesi telah menetapkan standar dan kompetensi yang diperlukan di kancah ASEAN. Oleh karenanya, dengan diberlakukannya MEA maka Indonesia 
akan menerima tenaga kerja dari ASEAN untuk profesi-profesi tersebut, demikian juga sebaliknya. Kedelapan profesi yang akan bersaing dalam MEA adalah sebagai berikut:

\section{Insinyur}

Salah satu profesi yang harus siap menghadapi MEA adalah Insinyur. Hal ini berlaku untuk semua insinyur, yang kalau di Indonesia memakai gelai ST alias Sarjana Teknik. Para Insinyur tersebut bergabung dalam organisasi profesi yang disebut Persatuan Insinyur Indonesia (PII). Saat ini ada 14 jenis profesi insinyur di Indonesia, mulai dari Insinyur mesin, insinyur geodesi, teknik fisika, teknik sinpil dan teknik kimia.

2. Arsitek

Arsitek adalah mereka yang memiliki ahli arsitektur, yaitu ahli rancang bangun atau ahli lingkungan binaan. Lingkup pekerjaan arsitektur sangat luas dan meliputi interior, lingkup bangunan, lingkup komplek bangunan, sampai dengan lingkup kota, dan regional. Posisinya yang strategis bahkan bisa membuat sebuah pembangunan dihentikan karena tidak sesuai dengan persyaratan yang sudah disepakati.

\section{Tenaga Pariwisata}

Tenaga paiwisata merupakan profesi yang sangat dibutuhkan di Indonesia karena potensi objek pariwisata Indonesia yang cukup banyak. Pada dasarnya, jenis tenaga kerja pariwisata cukup banyak karena banyaknya profesi yang berhubungan dengan sektor yang satu ini. Beberapa contoh di antaranya adalah bidang maskapai penerbangan yang mencakup agen tiket, pilot, pramugari, katering, dan lain-lain. Bisa juga bdang perhotelan, di mana yang terlibat adalah manger hotel, room service staff, controller, dan lain-lain.

4. Akuntan

Akuntan adalah mereka yang ahli di bidang akuntansi. Profesi akuntan dibedakan atas beberapa macam, di antaranya adalah akuntan publik, akuntan keuangan (financial), akuntansi biaya (cost), bahkan akuntan pajak (tax).

\section{Dokter Gigi}

Dokter gigi bertugas untuk melakukan pencegahan kerusakan dan penyakit pada gigi dan mulut. Saat ini yang mengambil profesi dokter gigi di Indonesia masih sedikit, sehingga banyak peluang kerja untuk profesi yang satu ini.

\section{Tenaga Survei}

Tenaga survei yang dimaksud disini adalah mereka yang ahli dalam bidang pengukuran bumi, dalam hal ini pengukuran tanah atau darat. Jadi bukan tenaga survei untuk pemilu atau badan survei yang selama ini sering kita dengar. Umumnya, tenaga survei atau surveyor berasal dari sekolahsekolah yang mengajarkan ilmu-ilmu pengukuran bumi, di antaranya adalah lulusan Teknik Geodesi dan Geomatika dari Universitas atau lulusan Sekolah Tinggi Pertanahan Nasional (BPN), dan instusi lain yang bergerak dalam kerekayasaan konstruksi. Hingga saat ini kebutuhan untuk tenaga survei masih sangat tinggi di Indonesia.

7. Praktisi Medis

Dengan masuknya praktisi medis dalam daftar profesi yang boleh keliling ASEAN, maka jangan heran jika kita nanti bertemu dengan dokter asing di sebuah rumah sakit di Indonesia.

\section{Perawat}

Selain Dokter dan dokter gigi, perawat juga memiliki kesempatan kerja di seluruh negara ASEAN bila mereka meiliki kompetensi yang meyakinkan plus jam terbang yang lumayan tinggi.

Oleh karenanya tantangan sekarang ini kedepan adalah pemerintah perlu melakukan pemetaan sumber daya manusia dengan memberikan intensif yang sesuai dengan profesionalisme yang mereka miliki agar 
lapangan-lapangan pekerjaan yang selama ini kekurangan bisa ditempati oleh human capital yang ada agar mereka bisa berkarya di negeri sendiri dengan kepala tegak karena memiliki kompetensi diri yang sejajar dengan kolegakoleganya di negara ASEAN.

Kesepakatan ASEAN Economic Community (AEC) yang telah ditandatangani dan mulai berlaku pada 2015. Harus segera disikapi melalui upaya pembenahan di sejumlah bidang dan sektor terkait dengan kinerja ekonomi nasional. Karena kalau tidak maka Indonesia hanya menjadi pasar bagi produk yang diproduksi oleh Negara lain seperti Singapura, Malaysia dan Thailand. Melalui komunitas ekonomi ASEAN disepakati akan dihapusnya segala bentuk tarif, jaminan mobilitas tenaga kerja yang berkualitas (skilled labor force) dan jaminan mobilitas modal. Belajar dari AseanChina Free Trade Agreement (AC-FTA), maka Indonesia perlu bergegas mempersiapkan diri menghadapi AEC.

Tantangan yang dihadapi Indonesia menyongsong diberlakukannya AEC tidaklah ringan. Ketersediaan dan kualitas infrastruktur baik di bidang jaringan logistik, energi, listrik dan konektivitas (jalan, pelabuhan, transportasi sungai) perlu segera ditingkatkan. Pemerintah memang telah menunjukkan keseriusan dalam pengembangan enam koridor ekonomi dan pelibatan BUMN untuk penyediaan dana dan proyek pembangunannya. Pekerjaan berikutnya adalah bagaimana implementasi dari rencana yang telah disusun dengan baik di tingkat nasional dapat direalisasikan.

Selain itu, tantangan lain ditemukan pada profil tenaga kerja nasional. Kualitas SDM yang kita miliki memang masih lebih didominasi oleh tenaga kerja tidak terampil (unskilled labor force). Data Biro Pusat Statistik menunjukkan sampai tahun 2009, jumlah tenaga kerja yang memiliki pendidikan tertinggi SD ke bawah sebesar 55.21 juta atau 52,65 persen dari total 104,87 juta orang. Sementara pekerja dengan pendidikan diploma hanya sebesar 2,79 juta (2,66\%) dan pendidikan tingkat sarjana berjumlah 4,66 juta orang (4,44\%). (Biro Pusat Statistik Tahun 2010)

Oleh karena tantangan kita dalam waktu yang tidak terlalu lama adalah bagaimana Indonesia mampu memproduksi tenaga kerja terampil melalui pendidikan di sejumlah sekolah kejuruan dan perguruan tinggi. Dalam hal ini Kementerian Pendidikan Nasional dan Kementerian Tenaga Kerja dan Transmigrasi perlu merancang program akselerasi bersama. Agar semakin banyak tenaga kerja Indonesia di tahun 2015 yang dapat memiliki kemampuan mobilitas di kawasan ASEAN.

Mobilitas modal yang bebas justru akan semakin meningkatkan pola persaingan untuk mendapatkan foreign direct investment (FDI) bagi negara-negara ASEAN. Pola kompetisi akan semakin tinggi ketika terdapat kesamaan bidang investasi. Misalnya untuk sektor pertanian dan pengolahannya persaingan dapat muncul antara Indonesia dengan Thailand. (Http://indonesia.rti.org "Kemenlu akan bentuk tim kerja ASEAN", Radio Taiwan International, 15 September 2008)

Tentunya iklim usaha yang baik dan ketiadaan high-cost-economy akan menentukan negara mana yang akan dipilih sebagai tempat berinvestasi. Dalam hal ini Indonesia sebenarnya memiliki keunggulan di mana terdapat konsumsi domestik yang cukup besar. Terlebih lagi ketika di akhir tahun 2014 GDP per kapita Indonesia bisa mencapai US\$ 5.000. Tentunya hal ini bisa menjadi faktor penarik bagi investor di sektor riil di Indonesia. (http://www.imf.org/external/datamapper/index .php)

Salah satu upaya yang dilakukan oleh pemerintah salah satunya adalah meningkatkan daya saing nasional, agar Indonesia bisa berperan aktif nantinya dalam MEA 2015. Daya saing nasional yang tercermin dalam peningkatan produktivitas dan efisiensi biaya produksi mutlak perlu terus dilakukan. Dalam hal ini, baik pemerintah maupun swasta 
nasional memiliki peran yang berbeda meskipun memiliki tujuan yang sama, yaitu daya saing nasional. Peran yang dapat dilakukan pemerintah, baik pusat dan daerah, adalah de-birokratisasi sejumlah perizinan usaha dan mengurangi tumpang tindih (overlapping) kebijakan pusat-daerah.

Dalam hal ini sinkronisasi kebijakan perlu segera dilakukan. Sejumlah daerah telah berhasil menyederhanakan prosedur perizinan melalui pemanfaatan teknologi dan penerapan e-government. Hal ini dapat menjadi bestpractice dan perlu disosialisasikan ke sejumlah daerah lain.

Peran swasta tentunya fokus terhadap pembenahan dan peningkatan kualitas produksi. Sehingga produk dan jasa yang dihasilkan akan mampu bersaing dengan produk dan jasa yang diproduksi negara lain di kawasan ASEAN. Peningkatan kualitas SDM, teknologi produksi, penguatan permodalan, keterkaitan industri (industrial linkage), R\&D, dan kemampuan membaca pasar perlu segera ditingkatkan.

Selain persoalan-persoalan diatas yang tidak kalah pentingnya adalah keberadaan UMKM sebagai salah satu penggerak perekonomian rakyat. Oleh karenanya Usaha Kecil dan Menengah (UKM) perlu mendapatkan intervensi pemerintah pusatdaerah untuk peningkatan produktivitas. Intervensi dapat dilakukan melalui pengembangan skema pembiayaan sampai kepada pembinaan UMKM. Hal ini tentunya agar ketika AEC diterapkan pada 2015, sudah tercipta lapisan UKM yang cukup besar dan memiliki kualitas produk yang dapat bersaing di tingkat regional.

Daya saing nasional dari suatu negara sering dikaitkan dengan beberapa parameter. Misalnya, daya saing nasional dikaitkan dengan nilai tukar mata uang dan tingkat suku bunga yang diberlakukan dan anggaran pemerintah. Ada juga yang meningkaitkan daya saing nasional suatu negara dengan jumlah angkatan kerja yang berlimpah dan murah. Lainnya, mengaitkan daya saing nasional dengan kelimpahan dan keragaman sumberdaya alam. Atau juga, mengaitkan daya saing nasional dengan kebijakan pemerintah dalam pencapaian target ekspor, promosi dagang, proteksi impor dan subsidi eskpor. Bahkan, ada yang mengaitkan daya saing nasional dengan praktek manajemen perusahaan, termasuk didalamnya relasi antara manajemen dengan pekerja. Singkatnya, terdapat banyak pendekatan yang diterapkan untuk memahami dan mendefinisikan daya saing nasional. Oleh karenanya hakekat dari daya saing nasional suatu Negara adalah seberapa besar tingkat pendapatan per kapita penduduknya.

Dari hasil riset dan studinya terhadap ekonomi negara-negara di dunia, Michael E. Porter, pakar manajemen dari Harvard University, menyimpulkan bahwa sumber utama peningkatan daya saing adalah produktivitas dan rata-rata peningkatan produktivitas. Lebih jauh lagi, Porter menandaskan bahwa sektor industri yang menjadi pendorong utama daya saing nasional. Melalui sektor industri, sumberdaya manusia, modal dan kekayaan alam dikelola dan dimanfatkan untuk memproduksi barang/jasa pada tingkat biaya yang efisien dan kualitas yang prima serta menjualnya ke pasar domestik dan global secara kompetitif.

Oleh karenanya menurut Porter bahwa kelimpahan sumberdaya alam tidak cukup untuk menciptakan daya saing suatu negara yang berujung pada standar hidup (living standard) yang tinggi. Sementara, daya saing makro ekonomi (macro economic competitiveness) hanya memberikan dukungan terhadap produktivitas suatu negara. Bagi Porter, produktivitas sepenuhnya tergantung pada perbaikan kapabilitas mikroekonomi dari suatu negara dan kecanggihan industri lokal.

Jadi, sesungguhnya sektor industri yang punya kaitan langsung dalam menciptakan lapangan pekerjaan, menambah penghasilan 
pekerja dan berperan penting dalam mengatasi kemiskinan. Ekonomi suatu negara yang memiliki daya saing adalah ekonomi yang ditopang dan digerakkan oleh industri yang kuat untuk melahirkan dari rahimnya perusahaan-perusahaan kelas dunia, yang tidak hanya mampu menahan gempuran pesaingpesaing asing di pasar domestik tapi juga mampu melakukan penetrasi dan memenangkan persaingan di pasar-pasar internasional/global. Perusahaan-perusahaan inilah yang menjadi ujung tombak dari daya saing nasional. Sebab, bagaimanapun yang bersaing secara head-to-head dengan produk asing adalah produk-produk yang dihasilkan oleh perusahaan-perusahan ini di manapun produk-produk tersebut dipasarkan baik di pasar domestik maupun di pasar global. Pada intinya, daya saing nasional sangat tergantung pada produktivitas perusahaan-perusahaan di berbagai industri dalam memproduksi barang/jasa secara lebih kompetitif dengan teknologi yang dikuasai anak bangsa serta bahan baku berbasis sumberdaya lokal.

Akan tetapi, peranan pemerintah dalam menumbuhkan daya saing suatu negara tidak bisa dikesampingkan. Pemerintah memiliki peran yang sangat penting, utamanya dalam mendesain dan mengimplementasikan berbagai kebijakan yang menawarkan lingkungan usaha kondusif kepada dunia bisnis. Pemerintah berperan menciptakan iklim usaha untuk memungkinkan dunia usaha tumbuh kuat dan bergerak lincah dalam berkompetisi dengan produsen asing. Begitu juga, sektor publik dan masyarakat harus memposisikan diri dalam memperkuat sektor industri. Sektor publik diharapkan mampu menyediakan berbagai infrastruktur dan pengelolaannya serta tingkat pelayanan yang cepat, akurat dan murah kepada sektor industri. Sementara itu, masyarakat berperan menyerap produk yang dihasilkan oleh sektor industri lokal melalui kemampuan daya beli dan pola konsumsi yang dimiliki. Masyarakat juga diharapkan menmbangun dan memperkuat aspek budaya (termasuk pendidikan) dan mentalitas/spiritual para warganya agar dapat melahirkan tenaga-tenaga kerja yang trampil, ulet dan berintegritas bagi sektor industri.

Dari perspektif ini menjadi jelas bahwa membangun daya saing nasional suatu negara bukanlah persoalan sederhana. Di sana mutlak perlu ditunjang oleh industrial structure yang tangguh. Yakni, suatu bagunan industri yang digerakan oleh perusahaan-perusahaan yang kokoh dalam sumber pendanaan/keuangan, ditopang oleh sumberdaya manusia kompeten, bergerak lincah dan cepat karena didukung kebijakan pemerintah yang kondusif terhadap lingkungan usaha, memiliki kemudahan akses bahan baku, menguasai teknologi secara handal, kuat dalam jaringan distribusi, mampu mengembangkan penelitian dan pengembangan terdepan untuk menelurkan produk inovatif, dan terakhir memiliki kepedulian terhadap kelangsungan lingkungan hidup (sustainable development).

Mencermati kondisi Indonesia, dalam presentasi Improving Indonesia's Competitiveness kepada Presiden RI di Boston pada 28 September 2009, Porter memberi beberapa catatan mengenai kekuatan dan kelemahan lingkungan bisnis Indonesia. Pertama, Kekuatan Indonesia terletak pada tersedianya jumlah angkatan kerja yang besar dengan tingkat kemampuan dasar yang kuat. Kedua, terlaksananya program reformasi hukum/perundang-undangan dan peraturan yang menciptakan iklim usaha kondusif bagi kalangan dunia usaha. Ketiga, terciptanya sistem keuangan solid yang menjamin ketersedian cadangan devisa memadai untuk menstabilkan nilai tukar rupiah terhadap mata uang asing, khususnya mata uang dari negaranegara kuat. Keempat, ketersedian Indonesia untuk membuka investasi luar negeri. Kelima, tersedianya ruang gerak yang luas bagi pembangunan cluster, khususnya di sektorsektor industri berbasis sumberdaya alam yang secara berlimpah dimiliki Indonesia.Hal terakhir ini bisa memberikan keunggulan 
komparatif (comparative adventage) bagi Indonesia.

\section{SIMPULAN}

Sehubungan dengan hal tersebut, Indonesia harus mampu memperbaiki lingkungan bisnis menjadi lebih kondusif bagi investor secara khusus bagi investor dalam negeri dan juga luar negeri agar terjadi kegiatan riil. Dalam persaingan industri/produk, tiga persyaratan umum harus dipenuhi agar dapat keluar menjadi pemenang persaingan, yaitu:

1. Menghasilkan suatu barang atau jasa dengan tetap memperhatikan mutu pada tingkat biaya yang paling efisien sehingga bisa bersaing dalam harga jualnya.

2. Diferensiasi dalam pengertian bahwa produk atau jasa yang dihasilkan mempunyai keunikan tersendiri dan mampu secara jitu mengkomunikasikan mutu dan harga produk untuk membangun dan menciptakan superior perceived value dibenak konsumen.

3. Cluster development dengan fokus untuk mengerjakan sesuatu bidang atau produk tertentu yang berbasiskan kelimpahan sumberdaya lokal yang dimiliki yang mempunyai keunggulan komparative ataupun kompetitif sehingga menghasilkan produk yang berbeda dan "superior perceived value" dengan penguasaan teknologi.

Dengan segala kekuatan dan kelemahannya, serta diberlakukannya MEA, Indonesia berada dalam posisi harus berhadapan dengan negara-negara Asean lainnya.MEA mendatangkan peluang bagi masing-masing negara dan sekaligus juga ancaman. Kenyataannya saat ini bahwa produk Indonesia secara umum belum mampu bersaing dengan produk-produk pertanian dari Thailand dan Vietnam, sehingga peningkatan daya saing produk industri nasional kita mutlak harus dilaksanakan. Seharusnya tingkat daya saing produk Indonesia dibandingkan dengan produkproduk dari negara-negara ASEAN, Chinadan negara lainnya yang telah menandatangani perjanjian perdagangan bebas (Free Trade Area) harus mempunyai daya saing yang minimal sama (equal) baru kita membuka perdagangan bebas untuk menghindari deindustrialisasi di dalam negeri yang dapat mengakibatkan Indonesia hanya sebagai pasar dan apabila hal ini terjadi akan mengakibatkan peningkatan jumlah pengangguran.

Dalam peningkatan daya saing produk industri nasional mutlak harus dilaksanakan secara komprehensif, mungkin dapat dimulai dari pembenahan kelemahan-kelemahan seperti yang disebutkan di atas pada tulisan ini dengan perencanaan, pelaksanaan serta menetapkan target yang dicapai mulai dari jenis produk, waktu dan lain-lain. Memang pemerintah saat ini sedang mengupayakan peningkatan daya saing produk industri nasional secara berkelanjutan (sustainable development) yang diharapkan dalam waktu yang tidak terlalu lama sudah membawa daya saing produk industri nasional menjadi minimal sama atau bahkan lebih baik dari produk negara-negara lainnya. 


\section{DAFTAR PUSTAKA}

ASEAN 2025: Forging Ahead Together, One Vision, One Identity, One Community, The ASEAN Secretariat, Jakarta, 2015.

Piagam ASEAN dan juga cetak biru Komunitas Ekonomi ASEAN 2015

Sjamsul Arifin, Rizal A. Djaafara, Aida S. Budiman, Masyarakat Ekonomi ASEAN 2015; Memperkuat Sinergi ASEAN di Tengah Kompetisi Global,Elex Media Komputindo, Jakarta 2007

http://www.lowyinterpreter.org/post/2010/06/2 9/Indonesia-as-ASEAN-Chair-A-test-of democracy.aspx

http://www.imf.org/external/datamapper/index. php

"Empat Anggota ASEAN Ratifikasi Piagam", Antara, 20 Februari 2008

"Kemenlu akan bentuk tim kerja ASEAN", Radio Taiwan International, 15 September 2008

http://internasional.kompas.com/read/2011/05/ 08/18560276/Akhir.Tahun.Nasib. Timor.Leste.di.ASEAN

http://www.deplu.go.id/Pages/Asean.

http://www.unisosdem.org/article_

http://www.monstersandcritics.com/news/asiap acific/news/article_1572678.php/SouthChina-Sea-dispute-in-spotlights-atASEAN-forum

http://www.2point6billion.com/news/2010/09/2 0/u-s-asean-leaders-to-discuss-south-chinasea-territorial-disputes-7192.html

http://www.chinadaily.com.cn/cndy/2010-

02/11/content_9460290.html 